\title{
Tamping Mortars with Stabilizing and Plasticizing Admixtures
}

\author{
Volodymir Terlyha, Khrystyna Sobol \\ National University "Lviv Polytechnic" \\ Institute of Building and Environmental Engineering, Highways Department \\ e-mail: vterlyha@gmail.com
}

\begin{abstract}
Boreholes cementing operations at the depth of several kilometers requires the best technology as well as the best materials. To produce the materials satisfying all the requirements concerning the tamping works is possible using the technology of dry building mixes (DBM) prepared at the factories by thorough mixing of accurately dosed components. Using of chemical admixtures allows improving some properties of these mixes.

In this work the influence of mineral fillers and chemical admixtures on the properties of the fresh mixture and hardened tamping mortar was investigated. It is established that introduction of the admixture with complex action on the basis of stabilizer Walocel 15-01 and plasticizer Melflux 2651 allows obtaining the fresh mixture with high spreadability. At the same time the value of dehydration approaches to zero which favorably effects on stabilization of fresh mixture and not allows the sedimentation processes to take place.

By the X-ray analysis, the positive influence of modification admixtures on the hydration processes in the tamping mortars by activating them was identified. In the result of this, the formation of hydrate phases is accelerated; these phases tightly mud the pore area of tamping stone increasing by this its strength.
\end{abstract}

Key words: dry building mixes, tamping mortar, admixture, spreadability, dehydration

\section{Introduction}

Nowadays it is impossible to imagine our life without usage of mineral products - oil and gas. Driving cars, heating houses, cooking meal - for all of these we use oil and gas. Mining of these recourses for industry requirements started in XIX century, but problems of boring casings cementing appeared with invention of rotor method drilling oil and gas boreholes [1]. With help of this method, rocks are crushed by uninterrupted process of crushing, carving and chipping with chisel. Reaching the needed depth, boring casings are put into a borehole. Inside of boring cases oil and gas are transported to the ground surface. The main target of cementing is to isolate stratum and to prevent oil and gas coming onto the ground surface, causing pollution.

Up to scientists information, oil that lies in investigated deposits is left for not more than 50 years. But thanks to progress of science and engineering, nowadays the process of well- 
drilling is developing at depths of $10000-15000$ meters. Boreholes with such depth are characterized by severity conditions: extremely high temperature and stratum pressure. Mining oil and gas at such depth demands usage of drilling, flushing and tamping materials with high quality $[2,3]$.

Mainly, for conducting cementing works the tamping Portland cements are used, and all chemical admixtures are added to mixture in liquid state near drilling site. This method can't guarantee planned result, because the possibility of mistake due to human factor arises. Obtaining of tamping materials with high quality is possible at the factories with high level mechanization according to the technology of dry building mixes (DBS). DBS - is a powdery material prepared at the factories by thorough mixing of accurately dosed components: cement, mineral fillers and chemical admixtures [4].

When pumping the fresh mixture into a borehole, it must create pressure not higher then stratum; if the pressure grows, the high possibility of hydraulic fracturing of stratum exists. To escape this situation, mortars with low density $1,4-1,65 \mathrm{gr} . / \mathrm{cm}^{3}$ are used [5]. It exist several ways of lowering the density of fresh mixture: increase the amount of water in tamping mortar, insertion of foam and gas generative admixtures, usage of organic binding materials, but still the main way is to insert mineral fillers with low density into the mix. The dispersed fillers of mineral and manufactured origin with high specific surface, such as microsilica, fly ash, perlit, zeolit, metakaolin and other, applies as these additives.

\section{Results of the investigation}

One of the criteria while choosing the tamping mortar to some borehole is technical properties of fresh mixture. In particular, dehydration of modern tamping materials must be about zero. Therefore, when choosing mineral additives the main attention must be paid to such properties as water absorbing, size and form of fractions, activeness of interaction with Portland cement and other. In this work several compositions of tamping mixes with different light-weight additives were investigated (Table 1).

Table 1: Compositions of tamping mixes

\begin{tabular}{|c|c|c|c|c|}
\hline $\begin{array}{l}\text { Components Composition } \\
\text { content, \% }\end{array}$ & 1 & 2 & 3 & 4 \\
\hline CEM I & 70 & 70 & 70 & 70 \\
\hline Metakaolin & 10 & 10 & 10 & 20 \\
\hline Microsphere & 20 & - & 10 & 10 \\
\hline Zeolit & - & 20 & 10 & - \\
\hline
\end{tabular}

Density of fresh mixture on basis of common Portland cement is $1,80-1,84 \mathrm{gr} / \mathrm{cm}^{3}$. Usage of mineral fillers leads to lowering of this index (fig. 1). Among the investigated additives, the most effective is microsphere, when inserting it in sum of $20 \%$, the density of fresh mixture 
is $1,42 \mathrm{gr} . / \mathrm{cm}^{3}$, water-hard ratio $(\mathrm{W} / \mathrm{H})$ is 0,57 . When inserting zeolite in the same sum the density of fresh mixture and $\mathrm{W} / \mathrm{H}$ are a bit higher $-1,61 \mathrm{gr} / \mathrm{cm}^{3}$ and 0,67 accordingly.

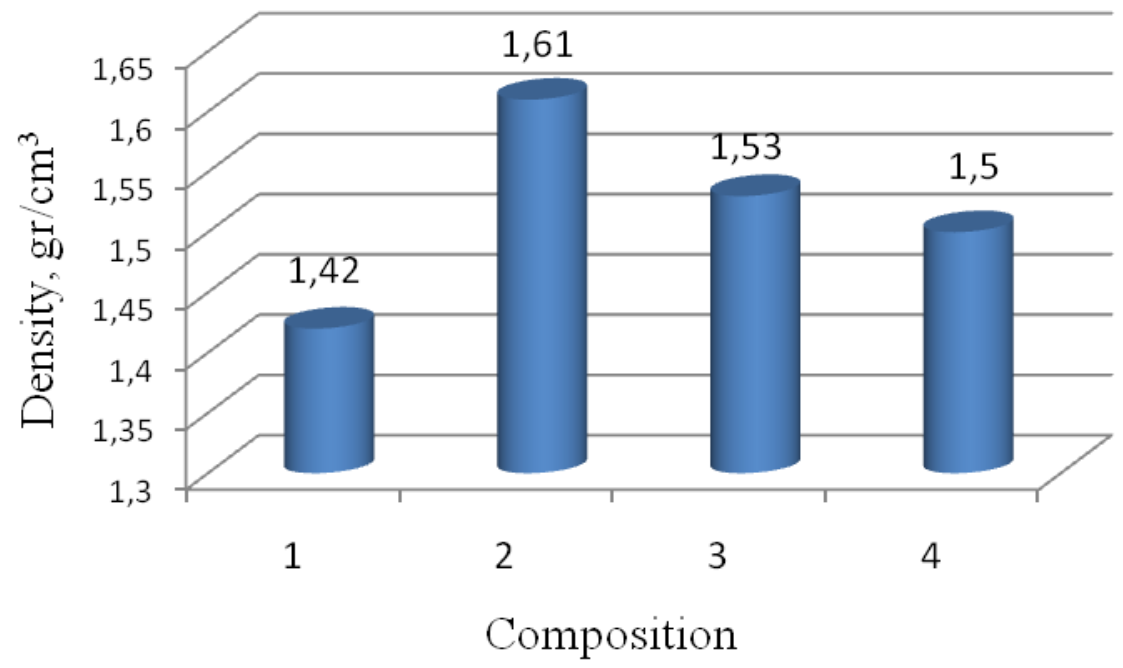

Figure 1: Influence of light-weight additives on density of fresh mixture

It is known, that one of the important properties of tamping mixes is dehydration. According to state standard of Ukraine, dehydration of light-weight tamping mixes must be not more than 7,5 ml. But, if tamping mix doesn't have sedimentation stability, i.e. its dehydration is high, it exfoliates by the highness of boreholes shaft under the influence of its own weight. This can leads to discontinuity of cement ring by physic-mechanical indexes and cause its destruction under influence of diffusive and corrosive processes. Therefore, dehydration of tamping materials of new generation must be equal zero. When inserting microsphere in sum of $20 \%$, dehydration of fresh mixture is $0 \mathrm{ml}$. When inserting zeolite in the same sum dehydration also isn't substantial and makes $1 \mathrm{ml}$, but it is known, that zeolite, comparing with microsphere, has high pozzolanic activity.

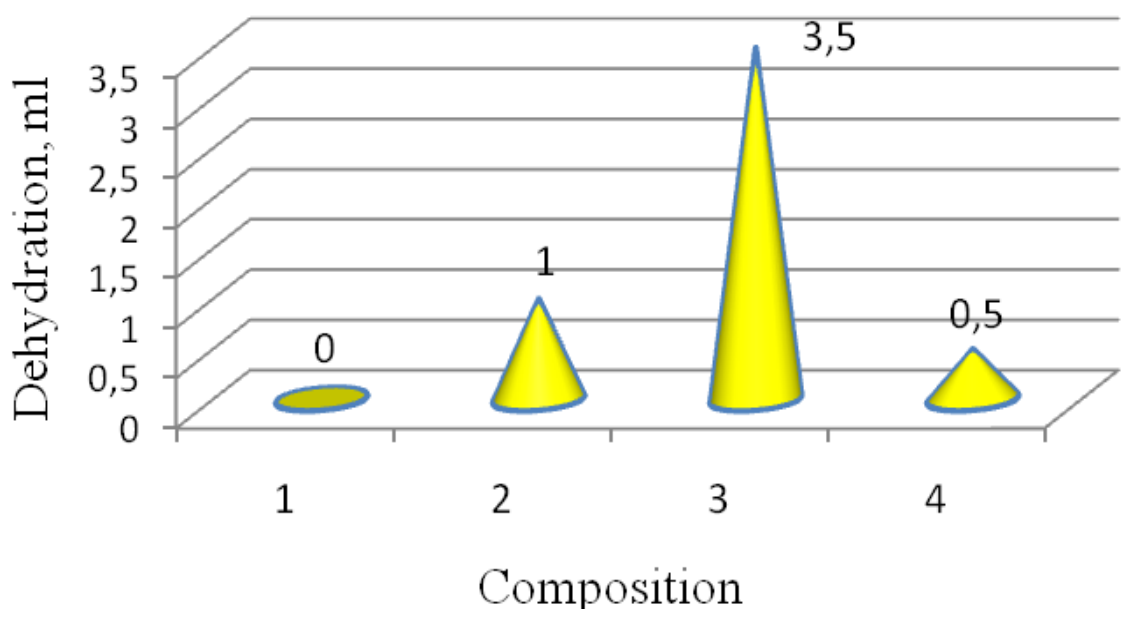

Figure 2: Influence of light-weight additives on dehydration of fresh mixture 
Tamping mixes must have sufficient spreadability. The more spreadability fresh mixture has the less probability that problems with pumping it to borehole will take place. Spreadability is characterized by possibility of fresh mixture delivering to necessary depth without its premature setting. Getting of necessary spreadability is attained by adding to composition system modern plasticizers. Plasticizers usage in dry building mixes is investigated very well [6], but in conditions of high temperature and pressure their properties can essentially change. To determine the influence of plasticizers on properties of tamping mix on a basis of lightweight Portland cement PCL-1 [7], which was developed on the basis of 2 composition (table 1), the admixtures Melflux 2651 and Melment F 10 were inserted to its composition (fig.3).The first of them owns better watereduction effect, its usage in sum of 0,1 mass $\%$, allows to obtain spreadability of $290 \mathrm{~mm}$, on account of not only electrostatic (plasticizer Melment F 10), but also steric effect, by adsorbsion of polycarboxylate ether hydrophobic chains on surface of cement particles. The mix with usage of chemical admixture Melment $\mathrm{F}$ 10 owns almost the same spreadability, but its concentration in composition is 0,6 mass $\%$.

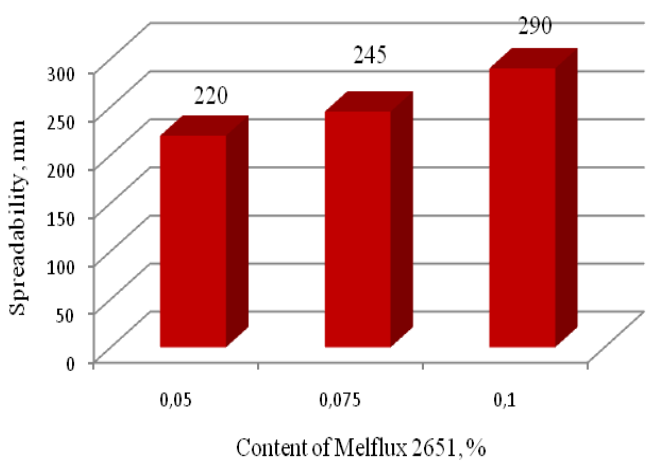

a

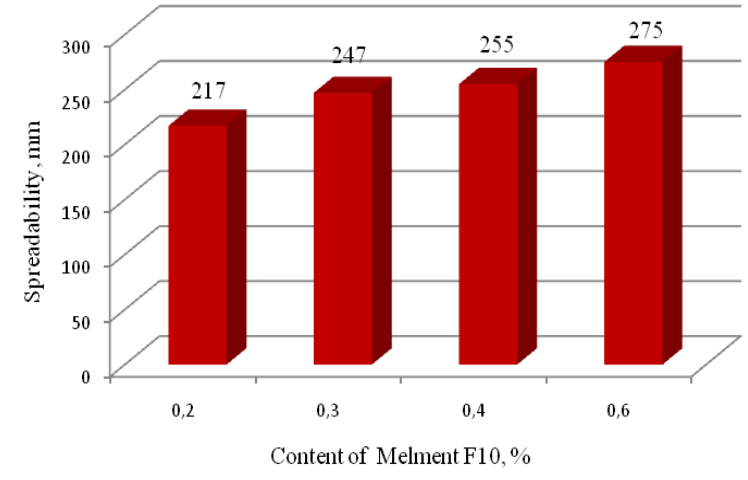

$\mathrm{b}$

Figure 3: Spreadability of fresh mixture with usage of admixture Melflux 2651

b) Melment F10

Usage of plasticizers causes considerable increasing of dehydration that leads to instability of system and appearence of fluidcondactive channels. Through them oil and gas can get to ground surface. This can causes environmental pollution, that, by-turn, can leads to considerable costs of borehole repairing works or even to its liquidation. To stabilize the fresh mixture and improve its sedimentation resistance water-retaining admixtures must be used. With this objective to composition on a basis of light-weight Portland cement PCL-1 were added admixtures on the basis of cellulose ester Walocel 15-01 and Walocel 400 that differ by various degree of viscosity. Each of them owns good water-retaining properties and with their usage dehydration of mix comes almost to zero (table 2). Cellulose esters are characterized by high solubility in water and surface activity. Forming water-resisting layer, they hold water in fresh mixture over a needed period. However, usage of admixture Walocel 15-01 in sum of 0,2 mass $\%$ and more is unreasonable, because spreadability of fresh mixture reduces to 195 $200 \mathrm{~mm}$. 
Table 2: Influence of stabilization admixtures on properties of fresh mixture on basis of PCL-1

\begin{tabular}{|c|c|c|c|c|c|}
\hline \multicolumn{3}{|c|}{$\begin{array}{c}\text { Content and name of admixture, [mass } \\
\% \text { ] }\end{array}$} & \multirow{2}{*}{$\begin{array}{l}\text { W/H } \\
0,67\end{array}$} & \multirow{2}{*}{$\begin{array}{c}\begin{array}{c}\text { Spreadability, } \\
{[\mathrm{mm}]}\end{array} \\
194\end{array}$} & \multirow{2}{*}{$\begin{array}{c}\text { Hydration, [ml] } \\
0,3\end{array}$} \\
\hline \multirow{3}{*}{$\begin{array}{l}0,1 \text { mass } \% \\
\text { Melflux }\end{array}$} & \multirow{2}{*}{$\begin{array}{c}\text { Walocel } \\
15-01\end{array}$} & 0,2 & & & \\
\hline & & 0,1 & 0,67 & 230 & 0,5 \\
\hline & $\begin{array}{l}\text { Walocel } \\
400\end{array}$ & 0,5 & 0,67 & 233 & 0 \\
\hline \multirow{3}{*}{$\begin{array}{l}0,6 \text { mass } \% \\
\text { Melment }\end{array}$} & \multirow{2}{*}{$\begin{array}{c}\text { Walocel } \\
15-01 \\
\end{array}$} & 0,2 & 0,67 & 218 & 0 \\
\hline & & 0,1 & 0,67 & 233 & 0,5 \\
\hline & $\begin{array}{c}\text { Walocel } \\
400\end{array}$ & 0,5 & 0,67 & 235 & 0,3 \\
\hline
\end{tabular}

The final aim of development of dry tamping mix with optimal content of chemical admixtures is getting a mortar with high technological and operational characteristics: low dehydration, sufficient spreadability, high bending strength and other. Most completely such properties ensure formulation of mixes with spreadability about $230 \mathrm{~mm}$ and dehydration about $0,5 \mathrm{ml}$. To get these properties the admixtures in such amount as it shown in table 3 were used.

Table 3: Compositions of tamping mixes on the basis of PCL-1 with chemical admixtures

\begin{tabular}{|c|c|c|c|c|}
\hline \multirow{2}{*}{$№$} & \multicolumn{4}{|c|}{ Content of admixtures, [mass \%] } \\
\cline { 2 - 5 } & $\begin{array}{c}\text { Melflux } \\
2651\end{array}$ & $\begin{array}{c}\text { Melment } \\
\text { F10 }\end{array}$ & $\begin{array}{c}\text { Walocel } \\
400\end{array}$ & $\begin{array}{c}\text { Walocel } \\
15-01\end{array}$ \\
\hline 1 & 0,1 & - & - & 0,1 \\
\hline 2 & 0,1 & - & 0,5 & - \\
\hline 3 & - & 0,48 & - & 0,1 \\
\hline 4 & - & 0,52 & 0,5 & - \\
\hline 5 & - & - & - & - \\
\hline
\end{tabular}

High strength of mortar in early terms of hardening enables to continue works of exploitation of borehole, that, by-turn, except costs connected with idle time of personal and technique, and this sum is equal about 6-8 thousand Euros per day. Insertion of a water-retaining admixture Walocel 400 to composition of mix leads to considerable decrease of mortars strength up to 3,05 and 4,1 $\mathrm{MPa}$ depending on selected plasticizer, versus composition without chemical admixtures (fig. 4). Usage of plasticizer Melment F10, besides low waterreduction effect, leads to mortars strength lowering. Plasticizer Melflux 2651 with high surface activity, doesn't effect on setting time of fresh mixture, which enables to reach a high strength in early times of hardening. The most optimal is the composition with usage of chemical admixtures Melflux 2651 and Walocel 15-01 in sum of 0,1 mass \%, which leads to improvement of rheological properties of fresh mixture and insignificant increase of mortars compression and bending tensile strength on $16,1 \%$ and $4,5 \%$ respectively. 


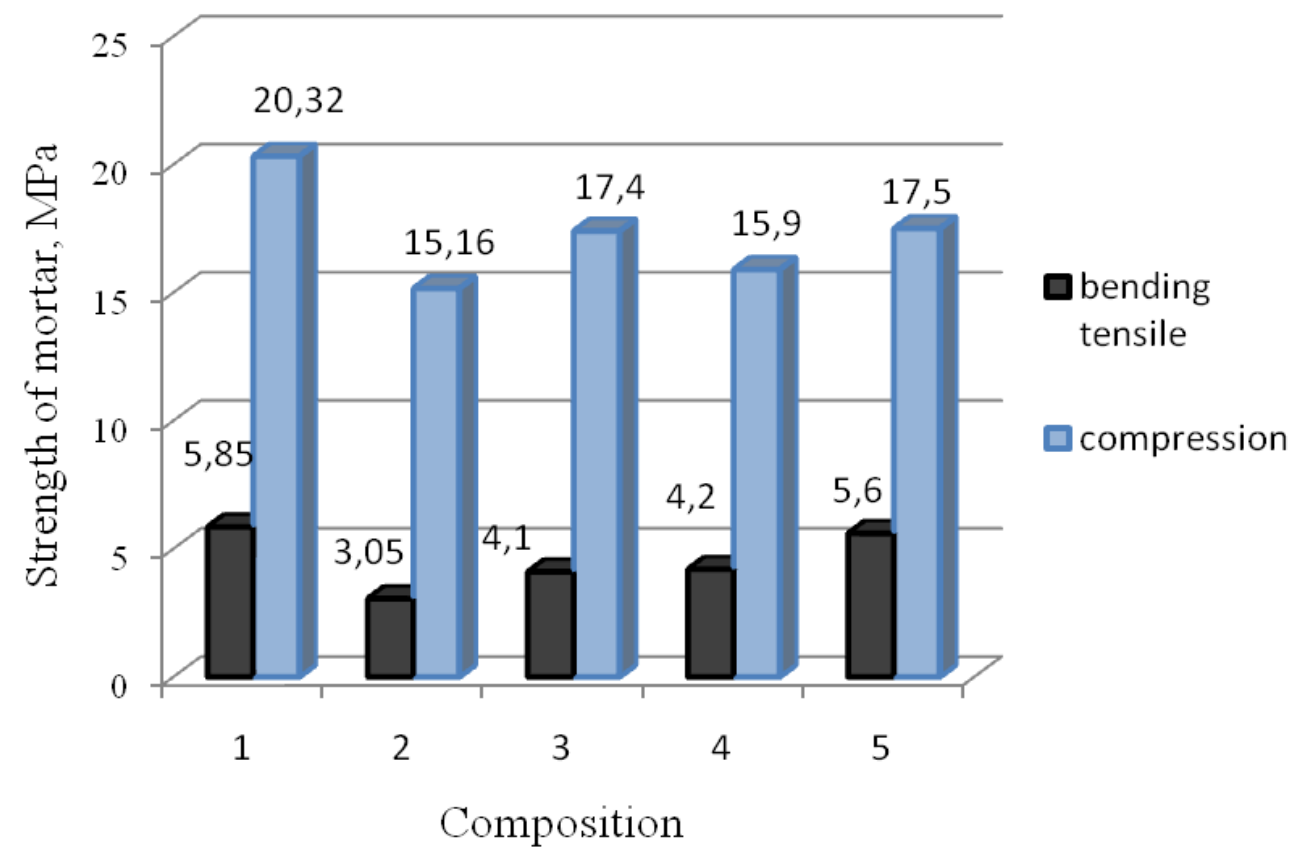

Figure 4: Influence of chemical admixtures on strength of tamping mortar on basis of PCL-1

To determine the effectiveness of used mineral additives and chemical admixtures, the X-ray analysis of common Portland cement, light-weight Portland cement (PCL-1) and light-weight Portland cement with chemical admixtures was carried out (fig. 5). On X-ray diffraction pattern of all investigated samples after 2 days of hardening at $75^{\circ} \mathrm{C}$ reflexes of non-hydrated clinker minerals are observed $(\mathrm{d} / \mathrm{n}=0,720 ; 0,276 ; 0,187 \mathrm{~nm})$, which intensity for mortars without additives are higher, than for mortars with organic and mineral additives. Content of calcium hydroxide $(\mathrm{d} / \mathrm{n}=0,490 ; 0,260 \mathrm{~nm})$ in compositions, that contain mineral additives is lower than in common cement mortar. This confirm active structure formative role of mineral additives - zeolite and metakaolin.

Insertion of complex chemical admixture that include plasticizer Melflux and water-retaining component Walocel to the composition of tamping cements leads to intensification of bending hydration processes with formation of structure-active phases, particularly hexagonal calcium hydroaluminate $(\mathrm{d} / \mathrm{n}=1,04 \mathrm{~nm})$.

Thereby, hydration processes of tamping mixes at $75^{\circ} \mathrm{C}$ are passing actively. In early period mortar oversaturated by calcium hydroxide is forming. In the system of polymineral tamping cements, due active $\mathrm{SiO}_{2}$ and $\mathrm{Al}_{2} \mathrm{O}_{3}$ presence, which are added by mineral additives - zeolite and metakaolin, their interaction with calcium hydroxide with formation of hydrate compounds passes.

Insertion of chemical admixtures in system of tamping cements is making a positive influence on hydration processes, activating them. In result of it, formation of hydrate phases, that tightly colmatate pore space of tamping stone, is fasted, increasing its strength. 

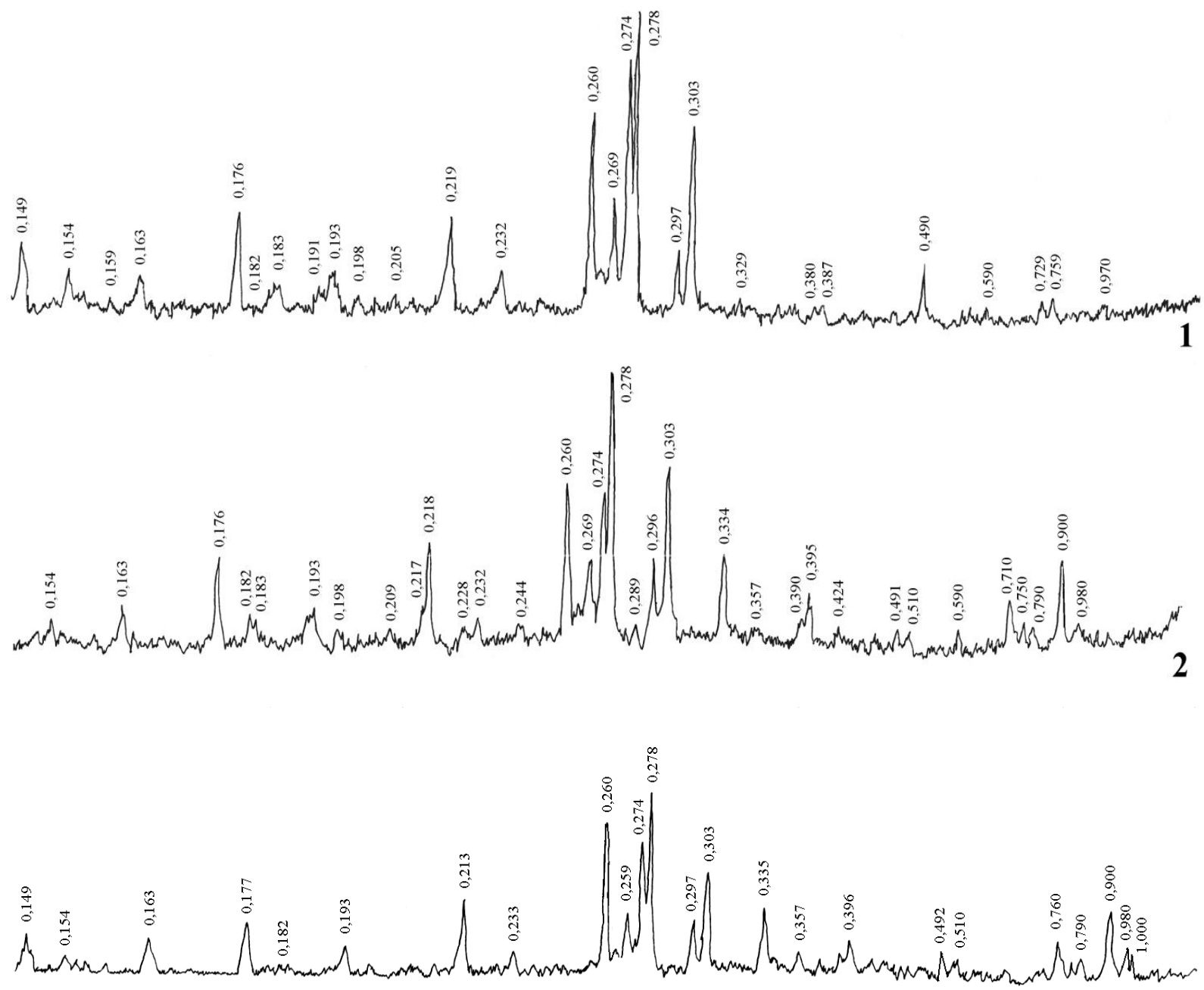

Figure 5: diffraction pattern of tamping stone, hydrated for 2 days at $75^{\circ} \pm 2^{\circ} \mathrm{C}$

1) without additives; 2) with $20 \%$ of zeolite and $10 \%$ of metakaolin; 3 ) with $20 \%$ of zeolite and $10 \%$ of metakaolin $+0,1 \%$ Melflux and $0,1 \%$ Walocel $15-01$.

\section{Conclusion}

Formulation of dry building mix, that has high technological properties, which secure qualitative cementing of borehole, was developed. Made investigations showed effectiveness of dry building mixes technology usage, when tamping materials are produced. High pozzolanic activity of light-weight mineral fillers zeolite and metakaolin, which bind free lime that is segregated in time of Portland cement hydration were proved by X-ray analysis. Optimal content of complex admixture, due high surface activity, proves rheological properties of fresh mixture and strength of tamping stone, was selected. 


\section{References}

[1] Bulatov, A. I., Makarenko, P. P., Proselkov, Yu. M. (1999). Drilling, flushing and tamping materials. Moscow: Nedra Ltd.

[2] Danyushevskiy, V. S., Aliev, R. M., Tolstyh, I. F. (1987). Reference book about tamping materials. Moscow: Nedra Ltd.

[3] Bulatov, A. I., Danyushevskiy, V. S. (1987). Tamping materials. Moscow: Nedra Ltd.

[4] Runova, R. F., Nosovskyi, Yu. L. (2007). Technology of modificated building. Kyiv.

[5] Horskyi, V. F. (2006). Tamping materials and mortars. Chernivtsi.

[6] Vasilik P, G., Golubev, I. V. (2006). Polycarboxylate systems in self-aligning compositions. Building Materials, 2006(3), 12-14.

[7] Terlyha, V. S. Facilitation of backfill mixes for the cementation of oil and gas pipes / $3^{\text {rd }}$ international conference of young scientists "Geodesy, architecture and construction". - Lviv, 25-27 November, 2010. - p. 102-103. 